\title{
Non-linear Causality Between Stock Returns And Inflation Uncertainty: Evidence From The US And The UK
}

Esin Cakan, University of New Haven, USA

\begin{abstract}
This study analyzes the dynamic relationships between inflation uncertainty and stock returns by employing the linear and non-linear Granger causality tests for the US and the UK. Using GARCH model to generate a measure of inflation uncertainty, it does not have a predictive power for stock returns, as predicted by Friedman, and it does not support the opportunistic central bank hypothesis suggested by Cukierman-Meltzer. However, the findings from non-linear Granger causality put forth that there is a bi-directional non-linear predictive power between these variables. Stock market is used as a hedge against inflation uncertainty.
\end{abstract}

Keywords: Stock Returns; Non-linear Granger-causality; Inflation Uncertainty; Granger-causality

\section{INTRODUCTION}

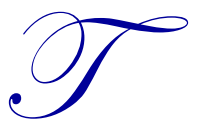

he validity of Friedman (1977)'s hypothesis, which argued that high inflation uncertainty caused by high inflation subsequently reduces economic efficiency by distorting price signals and may then negatively impact the level of real economic activity, is substantially discussed in the economic literature. The results are mixed for developed and developing countries. An alternative approach is CukiermanMeltzer's (CM) "opportunistic" hypothesis that higher inflation uncertainty raises the average inflation rate. The increase in nominal uncertainty raises the average inflation rate by increasing the incentive for the policy-makers to create inflation surprises which value the higher employment that results from surprise inflation. Both hypotheses put forth that inflation uncertainty affects the output growth. Conrad and Karanasos (2005) find mixed results for EU countries.

Empirical evidence in the literature supports the view that the stock market and economy are closely linked in the UK and the US which have established stock markets and are usually regarded as being financial marketbased economies. In both the UK and US, financial systems depend on a market-based system of control in which the market discipline comes from acquisitions and takeovers, not from the banking system. Therefore, the UK and US have a significantly closer relationship between stock prices and output and consumption (Morley, 2002). Moreover, Fischer and Merton (1984) showed that output and consumption are more strongly affected by the return on stocks than on bonds. Fama and Schwert (1977) investigate the assets which are hedges against the expected and unexpected components of inflation rate between 1953 and 1971 in the US. The most anomalous result of their study is that common stock returns are negatively related to the expected component of the inflation rate and also to the unexpected component. Their result supports the idea of Friedman's adverse output effect. Finding evidence for CM hypothesis supports the conclusion of Fama and Schwert that the stock market is not used as a hedge against inflation uncertainty.

This study investigates the linear and non-linear Granger causality relationships between stock market return and inflation uncertainty to test Friedman and CM hypotheses." 


\section{METHODOLOGY}

The study by Cecchetti and Krause (2001) reported that there has been progress in the macroeconomic performances of the developed and developing countries since the mid-1980s and inflation and inflation uncertainty are now more stable compared to prior to the mid-1980s. This case is also supported by the studies, such as Stock and Watson (2002), Fountas and Karanasos (2006), Fang and Miller (2008), and Ozdemir (2009). Besides macroeconomic developments, the inflation series of the considered countries was higher around the 1973 - the oil crisis period - than in other periods. Ozdemir (2009) also shows that there are two structural breaks in the inflation series of the UK - one corresponds to the mid-1980s and the other to the 1973 oil crisis. In the light of evidence of structural breaks within the series, a non-linear relation has to be taken into account when the relationship between inflation and inflation uncertainty is considered. The recent studies use linear Granger causality tests to check Friedman and CM hypotheses. The problem of linear approach to causality testing is that such tests generally have low power against non-linear Granger causality tests (Baek and Brock, 1992). Baek and Brock (1992) propose a non-parametric statistical method for uncovering a kind of non-linear causal relationship. Hiemstra and Jones (1994) modify the test of Baek and Brock (1992). Consider two stationary time series - $\left\{X_{t}\right\}$ and $\left\{Y_{t}\right\}, t=1,2, \ldots, T$. Denote the $m$-length lead vector of $X_{t}$ by $X_{t}^{m}$, and the $L x$-length and $L y$-length lag vectors of $X_{t}$ and $Y_{t}$, respectively, by $X_{t-L x}^{L x}$ and $Y_{t-L y}^{L y}$. For given values of $m, L x$, and $L y \geq 1$ and for $e>0, Y$ does not strictly Granger cause $X$ if:

$$
\begin{aligned}
& \operatorname{Pr}\left(\left\|X_{t}^{m}-X_{s}^{m}\right\|<e \mid\left\|X_{t-L x}^{L x}-X_{s-L x}^{L x}\right\|<e,\left\|Y_{t-L y}^{L y}-Y_{s-L y}^{L y}\right\|<e\right) \\
& =\operatorname{Pr}\left(\left\|X_{t}^{m}-X_{s}^{m}\right\|<e \mid\left\|X_{t-L x}^{L x}-X_{s-L x}^{L x}\right\|<e\right)
\end{aligned}
$$

where $\operatorname{Pr}(\bullet)$ denotes probability and $\|\bullet\|$ denotes the maximum norm. A test based on the equation above can be implemented as follows:

$$
\frac{C_{1}(m+L x, L y, e)}{C_{2}(L x, L y, e)}=\frac{C_{3}(m+L x, e)}{C_{4}(L x, e)}
$$

where $C_{1}, C_{2}, C_{3}$, and $\mathrm{C}_{4}$ are the correlation-integral estimators of the joint probabilities under the assumption that $\left\{X_{t}\right\}$ and $\left\{Y_{t}\right\}$ are strictly stationary and weakly dependent. If $\left\{Y_{t}\right\}$ does not strictly Granger cause $\left\{X_{t}\right\}$, then

$$
\sqrt{n}\left[\frac{C_{1}(m+L x, L y, e, n)}{C_{2}(L x, L y, e, n)}-\frac{C_{3}(m+L x, e, n)}{C_{4}(L x, e, n)}\right] \rightarrow N\left(O, \sigma^{2}(m, L x, L y, e)\right.
$$

where $\sigma^{2}(m, L x, L y, e)$ and an estimator discussed details in Hiemstra and Jones. Under the null hypothesis of non-linear Granger causality, the test statistics is asymptotically distributed by $N(0,1)$.

\section{DATA AND EMPIRICAL RESULTS}

To test for the relationships between stock returns and inflation uncertainty for the US and UK, as these countries represent the most financially capitalized markets, monthly data on the Consumer Price Index (CPI) are obtained from the International Financial Statistics (IFS) database as proxies for the price level. The data range is from 1957:01 to 2006:09 for the US and from 1984:01 to 2006:09 for the UK. The monthly CPI series used in this study has a monthly seasonal pattern. Hence, the monthly CPI series is deseasonalized. The inflation series is measured by the monthly difference of the $\log \mathrm{CPI}_{\mathrm{t}}\left[\pi_{\mathrm{t}}=100 . \log \left(\mathrm{CPI}_{\mathrm{t}} / \mathrm{CPI}_{\mathrm{t}-1}\right)\right]$. Stock price indices are monthly. FTSE100 and S\&P 500 index values are obtained from Datastream for the US and UK, respectively. Stock price return is measured by the monthly difference of the $\log \operatorname{INDEX}_{\mathrm{t}}\left[\mathrm{r}_{\mathrm{t}}=100 \cdot \log \left(\operatorname{INDEX}_{\mathrm{t}} / \mathrm{INDEX}_{\mathrm{t}-1}\right]\right.$. The AR( $(k)-$ $\operatorname{GARCH}(p, q)$ model generating the inflation uncertainty is used. In the $\operatorname{AR}(k)-\operatorname{GARCH}(p, q)$ model, the mean equation is defined as: 


$$
\pi_{t}=\beta_{0}+\sum_{i=0}^{k} \beta_{i} \pi_{t-i}+\varepsilon_{t}
$$

where $\pi_{t}$ denotes inflation and $\varepsilon_{t}$ is conditionally normal with mean zero and variance $h_{\pi t}^{2}$. In other words, $\varepsilon_{t} \mid \Omega_{t-1} \sim N\left(0, h_{\pi t}^{2}\right)$, where $\Omega_{t-1}$ is the information set up to time $t-1$. The structure of the conditional variance is:

$$
h_{\pi t}^{2}=c+\sum_{i=1}^{p} \alpha_{i} \varepsilon_{t-i}^{2}+\sum_{j=1}^{q} \delta_{j} h_{\pi, t-j}^{2}
$$

where $c$ is a positive constant and $\left(\sum_{i=1}^{p} \alpha_{i}+\sum_{j=1}^{q} \delta_{j}\right)<1$. We test for the stationarity properties of our data using the Augmented Dickey Fuller test and find both series are stationary. Table 1 summarizes the properties of the data set, Table 2 presents the inflation uncertainty summary statistics, and Table 3 shows that the data set is

\begin{tabular}{|c|c|c|c|c|c|c|c|c|c|c|c|}
\hline Countries & $\mu$ & $\sigma$ & $S$ & $\boldsymbol{K}$ & JB & $Q_{6}$ & $Q_{12}$ & $Q_{6}^{2}$ & $Q_{12}^{2}$ & $\begin{array}{l}\text { ARCH- } \\
\operatorname{LM}(6)\end{array}$ & $\begin{array}{l}\text { ARCH- } \\
\text { LM(12) }\end{array}$ \\
\hline UK & 0.206 & 0.221 & $\begin{array}{l}.23 * \\
(0.00)\end{array}$ & $\begin{array}{l}11.28^{*} \\
(0.00)\end{array}$ & $\begin{array}{l}3666.1^{*} \\
(0.00)\end{array}$ & $\begin{array}{l}1095.2^{*} \\
(0.00)\end{array}$ & $\begin{array}{l}1848.2^{*} \\
(0.00)\end{array}$ & $\begin{array}{l}129.8^{*} \\
(0.00)\end{array}$ & $\begin{array}{l}156.6^{*} \\
(0.00)\end{array}$ & $\begin{array}{l}157.4^{*} \\
(0.00)\end{array}$ & $\begin{array}{l}160.5^{*} \\
(0.00)\end{array}$ \\
\hline USA & 0.144 & 0.128 & $\begin{array}{l}1.01^{*} \\
(0.00)\end{array}$ & $\begin{array}{l}2.37^{*} \\
(0.00)\end{array}$ & $\begin{array}{l}241.1 * \\
(0.00)\end{array}$ & $\begin{array}{l}1127.8^{*} \\
(0.00)\end{array}$ & $\begin{array}{l}2090.9^{*} \\
(0.00)\end{array}$ & $\begin{array}{l}514.3^{*} \\
(0.00)\end{array}$ & $\begin{array}{l}849.1 * \\
(0.00)\end{array}$ & $\begin{array}{l}297.7^{*} \\
(0.00)\end{array}$ & $\begin{array}{l}310.6^{*} \\
(0.00)\end{array}$ \\
\hline
\end{tabular}
stationary.

Notes: $\mu$ denotes the average inflation rate for the period February 1957-October 2006 for the US and UK and $\sigma$ its standard deviation. $S$ and $K$ are the estimated skewness and kurtosis, respectively. JB is the Jarque-Bera statistic for normality. The columns beneath " $Q_{(m)}$ " and " $Q_{(m)}^{2}$ " give the Ljung-Box test statistics for inflation and the squared deviations of the inflation rate from its sample mean for up to $m$ th order serial correlation, respectively. The "ARCH-LM $(m)$ " gives the ARCH-LM test statistics for the series for up to $m$ th order of ARCH effects. Numbers in parentheses are $p$-values indicating significance at the 0.05 level.

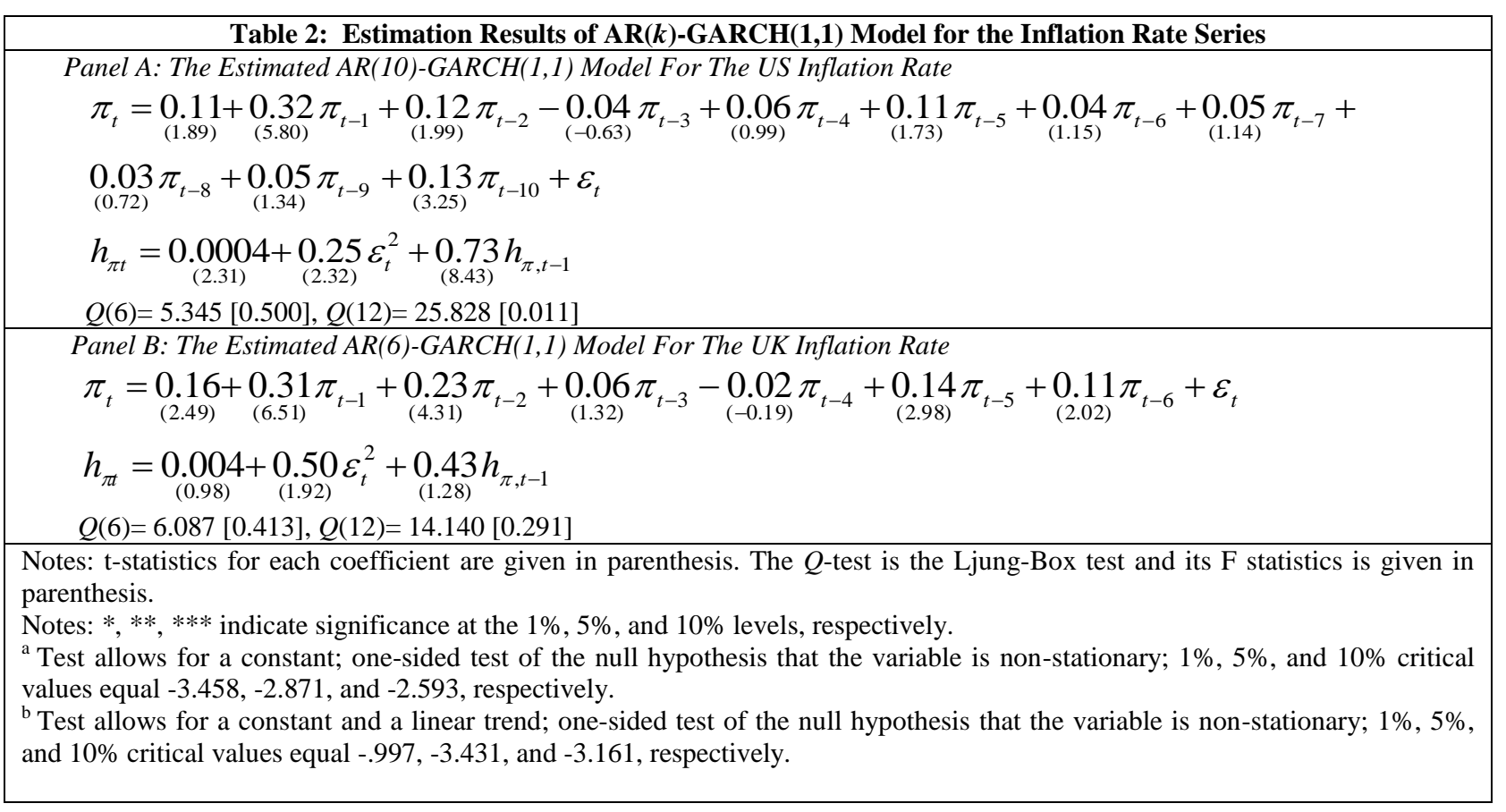




\begin{tabular}{|c|c|c|}
\hline \multicolumn{3}{|c|}{$\begin{array}{c}\text { Table 3: Unit Root Test Results for the Inflation and Stock Return Series } \\
\text { Level }\end{array}$} \\
\hline Series & $Z(t \mu)^{a}$ & $Z(t)^{b}$ \\
\hline Inflation of the UK & $-11.199 *(2)$ & $-11.364 *(5)$ \\
\hline Inflation uncertainty of the UK & $-9.692 *(0)$ & $-10.331 *(3)$ \\
\hline Inflation of the US & $-10.199 *(2)$ & $-10.232 *(0)$ \\
\hline Inflation uncertainty of the US & $-5.532 *(4)$ & $-5.623 *(1)$ \\
\hline FTSE100 Return & $-16.25 *(2)$ & $-16.31 *(0)$ \\
\hline S\&P 500 Return & $-23.1 * \quad(1)$ & $-23.2 *(1)$ \\
\hline
\end{tabular}

\section{Testing Linear Granger Causality}

Generalized autoregressive conditional heteroskedasticity (GARCH) models, introduced by Engle (1982) and Bollerslev (1986), allow us to proxy uncertainty using the conditional variance of unpredictable shocks to the inflation. The result of the causality of the linear relationship in the literature is mixed. Examined is the linear Granger causality, which requires that all data series involved are stationary; otherwise the inference from the Fstatistic might be spurious because the test statistics will have non-standard distributions (Granger, 1998). The pairwise Granger causality test results, given in Table 4, show that inflation does not Granger cause stock returns for 4 lags at 5 percent significance level for both countries. This result indicates that neither the Friedman nor the CM hypotheses are valid for the US and UK.

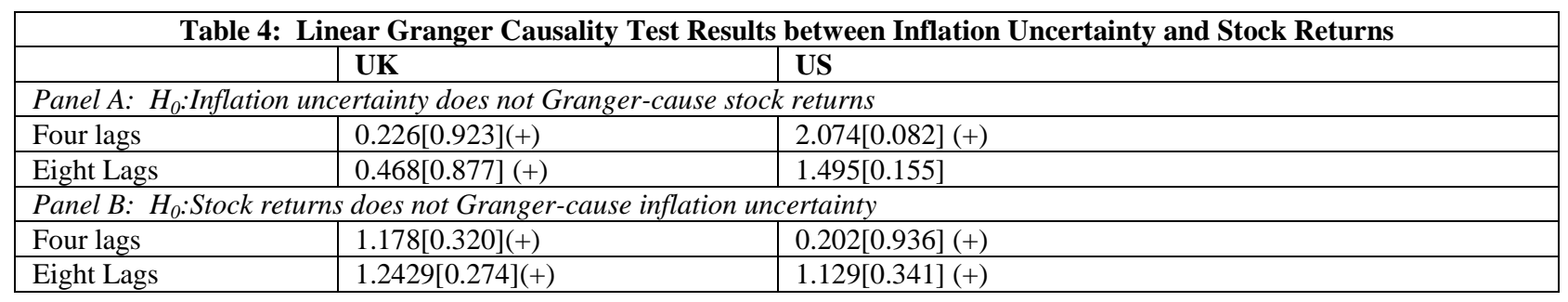

\section{Testing for Non-linear Granger Causality}

The problem of linear approach to causality testing is that such tests can have low power detecting certain kinds of non-linear causal relations (Baek and Brock, 1992). The interest in uncovering non-linear casual relationships started with Baek and Brock who proposed a non-parametric statistical method for uncovering these relationships.

Their approach uses the correlation integral, an estimator of spatial probabilities across time, to detect relations between time series. Using their model, non-linear casual relations have been found between money and income (Baek and Brock, 1992), aggregate stock returns and macroeconomic factors (Hiemstra and Kramer, 1993), and producer and consumer price indices (Jaditz and J. Jones, 1993). Hiemstra and Jones (1994) modify Baek and Brock's test to allow the variables to which the test is applied to exhibit short-term temporal dependence, rather than the Baek and Brock assumption that the variables are mutually independent and identically distributed.

Given the potential existence of a non-linear relationship between inflation uncertainty and stock returns for the UK and US, the non-linear Granger causality tests (Baek and Brock, 1992) are performed on the series to examine the relationship between inflation uncertainty and stock returns. Following Baek and Brock (1992), values of parameters, including lead length $(\mathrm{m})$, lag order $(L)$, and distance $(e)$, are set as $m=1, e=1$, and $L=4,8$, respectively. Table 5 reports that the results of non-linear Granger causality relation between inflation uncertainty and stock returns can be found in two countries - the UK and US. For both countries, inflation significantly Granger causes stock returns and stock returns significantly Granger cause inflation uncertainty when lag order is 4; in other words, a bi-directional causality running from inflation uncertainty to stock returns and vice versa. 
Table 5 presents the results of Hiemstra and Jones's (1994) non-linear Granger causality test for inflation and its uncertainty. The results show that inflation uncertainty non-linear Granger causes stock price returns at 5 percent significance level for Japan and at 4 and 8 lags for the UK and US. On the other hand, inflation uncertainty non-linear Granger causes stock market returns for all countries at 4 and 8 lags at 5 percent significance level, except for Japan at 8 lags. This result shows that there is a bi-directional non-linear Granger causality between both series with the latter finding. Table 6 represents the non-linear Granger causality test results for inflation uncertainty and stock market returns. At lag 4, the null hypothesis that inflation uncertainty does not granger cause stock returns is rejected at 5\% significance level for all countries. Therefore, it is concluded that at lag 4, there is bi-directional relationship between these variables, contrary to the result of linear models. Stock market returns is used as a proxy of output and the results are supporting the claim that inflation uncertainty changes the stock market returns and visa versa.

\begin{tabular}{|c|c|c|c|c|}
\hline \multicolumn{5}{|c|}{ Table 5: Pair-wise Non-linear Granger Causality Tests between the Inflation Uncertainty and Stock Returns } \\
\hline Countries & Null Hypothesis & $L y=L x$ & CS & TVAL \\
\hline \multirow{4}{*}{ UK } & $\boldsymbol{h}_{\pi t} \neq>r_{t}$ & 4 & 0.006 & $1.87^{*}$ \\
\hline & $r_{t} \neq>h_{\pi t}$ & 4 & 0.003 & $1.87^{*}$ \\
\hline & $\boldsymbol{h}_{\pi t t} \neq>r_{t}$ & 8 & 0.004 & 1.59 \\
\hline & $r_{t} \neq>h_{r t}$ & 8 & 0.002 & 1.61 \\
\hline \multirow{4}{*}{ US } & $\boldsymbol{h}_{\pi t} \neq>\boldsymbol{r}_{t}$ & 4 & 0.005 & $2.04 * *$ \\
\hline & $\boldsymbol{r}_{t} \neq>\boldsymbol{h}_{\pi t}$ & 4 & 0.003 & $1.87 *$ \\
\hline & $\boldsymbol{h}_{\pi t} \neq>\boldsymbol{r}_{t}$ & 8 & 0.004 & 1.59 \\
\hline & $r_{t} \neq>h_{r t}$ & 8 & 0.003 & 1.61 \\
\hline \multicolumn{5}{|c|}{$\begin{array}{l}\text { Notes: This table provides the results of the modified Baek and Brock test statistics applied for the inflation and its uncertainty. } \\
\text { CS and TVAL are the difference between the two conditional probabilities in Equation }(4) \text { and the standardized test statistic in } \\
\text { Equation (5), respectively. } \\
\dagger, * * * \text { denote rejections of the null hypothesis at } 10 \%, 5 \% \text {, and } 1 \% \text { significance levels, respectively; and the symbol " } \neq>\text { " implies } \\
\text { does not non-linear-Granger cause. The test statistic is asymptotically distributed } N(0,1) \text {. The critical values at } 10 \%, 5 \% \text {, and } 1 \% \\
\text { significance levels are } 1.64,1.96 \text { and } 2.33 \text {, respectively. }\end{array}$} \\
\hline
\end{tabular}

\section{CONCLUSION}

Inflation uncertainty has real effects only if it leads to output losses. To test such effects, we have used the stock market returns to proxy output. Our GC results indicate that inflation uncertainty causes output growth. In this study, the relationship between inflation uncertainty and stock returns has been investigated in G3 countries for the period 1957-2006 for the US and 1984-2006 for the UK. In contraction to linear results, the non-linear Granger causality test results show a bi-directional non-linear Granger causality between inflation uncertainty and stock returns. Stock market is also used as a hedge against inflation uncertainty, supporting Morley (2002).

\section{AUTHOR INFORMATION}

Dr. Esin Cakan is an Assistant Professor at Department of Economics, University of New Haven. She got her Ph. D. in Financial Economics from The Graduate School and University Center of City University of New York. Her main research interests are exchange rate markets, macroeconomics, and financial markets with a specific interest in financial econometrics. E-mail: ecakan@newhaven.edu

\section{REFERENCES}

1. Alesina, Alberto and Lawrence H. Summers (1993), "Central bank independence and macroeconomic performance: some comparative evidence", Journal of Money, Credit and Banking 25: 51-162.

2. Baek, Ehung and William Brock (1992), "A General Test for Non-linear Granger Causality: Bivariate Model", Working Paper, Iowa State University and University of Wisconsin, Madison, WI. 
3. Baillie, Richard T., Tim Bollerslev, and Hans O. Mikkelsen, (1996), "Fractionally integrated generalized autoregressive conditional heteroskedasticity", Journal of Econometrics 74(1): 3-30.

4. $\quad$ Ball, Laurence (1992), "Why does high inflation raise inflation uncertainty?", Journal of Monetary Economic 29: 371-388.

5. Bollerslev, Tim (1986), "Generalised Autoregressive Conditional Heteroskedasticity", Journal of Economics 31: 307-326.

6. Berument, Hakan (1999), "The impact of inflation uncertianty on interest rates in the UK", Scottish Journal of Political Economy 46: 207-218.

7. Berument, Hakan and Nergis Dincer (2005), "Inflation and Inflation Uncertainty in the G-7 Countries", Physica A 348: 371-379.

8. Berument, Hakan, Ali Inamlik, and Hasan Olgun (2008), "Inflation and Growth: Positive or Negative Relationship?", Journal of Applied Sciences 8(2): 192-204.

9. Brunner, Allan D. and Gregory D. Hess (1993), "Are higher levels of inflation less predictable? A statedependent conditional heteroscedasticity approach", Journal of Business and Economic Statistics 11: 187197.

10. Caporale, Tony and Barbara McKierman (1997), "High and variable inflation: further evidence on the Friedman hypothesis", Economics Letters 54: 65-68.

11. Campbell, John Y. and Pierre Perron (1991), "Pitfalls and Opportunities: What Macroeconomists Should Know about Unit Roots",O.J. Blanchard and S. Fischer (eds.) NBER Macroeconomic Annual 141-201, The MIT Press.

12. Conrad, Christian and Menelaos Karanasos (2005), "On the inflation-uncertainty hypothesis in the USA, Japan and the UK: a dual long memory approach", Japan and the World Economy 17: 327 - 343.

13. Cukierman, Alex and Allan H. Meltzer (1986), "A theory of ambiguity, credibility, and infation under discretion and asymmetric information", Econometrica 54: 1099-1128.

14. Daal, Elton, Naka Atsuyuki and Benito Sanchez (2005), "Re-examining inflation, inflation uncertainty in developed and emerging countries", Economic Letters 89: 180-186.

15. Dotsey, M., Sarte, P., 2000. Inflation uncertainty and growth in a cash-in-advance economy. Journal of Monetary Economics 45 (3), $631 \mathrm{e} 655$.

16. Engle, Robert F. (1982),"Autoregressive Conditional Heteroscedasticity with Estimates of the Variance of United Kingdom Inflation", Econometrica 50: 987-1007.

17. Engle, Robert F. (1983), "Estimates of the variance of US inflation based upon the ARCH model", Journal of Money, Credit and Banking 15: 286-301.

18. Fama, F. Eugene and G. William Schwert (1977) Asset returns and inflation, Journal of Financial Economics, Volume 5, Issue 2, November 1977, Pages 115-146.

19. Fischer, S. and Merton, R. (1984) Macroeconomics and Finance: the role of the stock market, CarnegieRochester Conference Series on Public Policy, 21.

20. Friedman, Milton (1977), "Nobel lecture: Inflation and Unemployment", Journal of Political Economy 85: 451-472.

21. Foster, Edward (1978), "The variability of inflation", Review of Economics and Statistics 60: 346-350.

22. Fountas, Stilianos., A. Ioannidis, and Menelaos Karanasos, 2004 Inflation, Inflation Uncertainty and a Common European Monetary Policy, Manchester School 72(2): 221-242.

23. Fountas, Stilianos and Menelaos Karanasos, 2007 Inflation, output growth, and nominal and real uncertainty: Empirical evidence for the G7, Journal of International Money and Finance 26, 229-250.

24. Garcia, Rene and Pierre Perron (1996), "An analysis of the real interest rate under regime shifts", Review of Economics and Statistics 83: 111-125.

25. Granger, Clive W. J. (1969), "Investigating Causal Relations by Econometrics Models and Cross Spectral Methods", Econometrica 37: 424-438.

26. Granger, Clive W. J. (1988), "Some Recent Developments in A Concept of Causality", Journal of Econometrics 39: 199-211.

27. Granger, Clive W. J. (1989), Forecasting in Business and Economics, 2nd ed., Academic Press, San Diego.

28. Grier, Kevin B. and Mark J. Perry (1998), "On inflation and inflation uncertainty in the G7 countries", Journal of International Money and Finance 17: 671-689.

29. Härdle, Wolfgang (1994), Applied Nonparametric Regression, Cambridge University Press. 
30. Hiemstra, Craig and Charles F. Kramer (1993), "Non-linearity and endogeneity in macro-asset pricing", Working Paper, University of Strathclyde and International Monetary Found.

31. Hiemstra, Craig and Jonathan D. Jones (1994), "Testing for linear and non-linear Granger causality in the stock price--volume relation", Journal of Finance 5: 1639--1664.

32. Holland, Steven (1995), "Inflation and uncertainty: tests for temporal ordering", Journal of Money, Credit, and Banking 27: 827-837.

33. Hwang, Yung (2001), "Relationship between inflation rate and inflation uncertainty", Economics Letters, $73,179-186$.

34. Jaditz, Ted and Jonathan Jones. (1993), "Granger causality between the consumer and wholesale price indicies", Working Paper, Bureau of Labor Statistics and Securities and Exchange Commision.

35. Laurent, S. and J. P. Peters, (2002), "G@RCH 2.2: an Ox package for estimating and forecasting various ARCH models", Journal of Economic Surveys 3: 447-485.

36. McLeod, Allan I. and William K. Li (1983), "Diagnostic checking ARMA time series models using squared residual autocorrelations", Journal Time Series Analysis 4: 269--73.

37. Morley, Bruce (2002), "Output, consumption and the stock market implications for European convergence", Applied Economics, 2002, 34, 317-323.

38. Ozdemir, Zeynel A. and Mahir Fisunoglu (2008), "On the inflation-uncertainty hypothesis in Jordan, Philippines and Turkey: A long memory approach", International Review of Economics and Finance 17: 112.

39. Pourgerami, A., Maskus, K., 1987. The effects of inflation on the predictability of price changes in Latin America: some estimates and policy implications. World Development 15 (1), 287e290.

40. Phillips, Peter C. and Pierre Perron (1988), "Testing for a unit root in time series regression", Biometrica 75: 335-346.

41. Stilianos Fountas a, Menelaos Karanasos (2007), Inflation, output growth, and nominal and real uncertainty: Empirical evidence for the G7, Journal of International Money and Finance 26 229-250. 
NOTES 